Esta obra forma parte del acervo de la Biblioteca Jurídica Virtual del Instituto de Investigaciones Jurídicas de la UNAM www.juridicas.unam.mx

\title{
EL PROBLema deL PRINCIPIO DE LA PARIDAD DE GÉNERO EN MATERIA ELECTORAL: ¿DE PUNTO DE PARTIDA A PUNTO DE LLEGADA? ${ }^{1}$
}

\author{
Imer B. Flores ${ }^{2}$
}

Cellui ou celle en qui plus a vertus est le plus hault, ne la haulteur ou abbaisement des gens ne gist mie es corps selon le sexe mais en la perfeccion des meurs et des vertus.

Christine de Pizan, La cité de les dames (c.1405)

\begin{abstract}
1 Versión revisada de texto homónimo publicado como Documento de Trabajo, núm. 189, México, UNAM, Instituto de Investigaciones Jurídicas, 2015, y que corresponde a las ponencias presentadas en: 1) Seminario Interno del Área de Derecho Electoral y Procesos Democráticos, México, UNAM, Instituto de Investigaciones Jurídicas, 5 de noviembre del 2015; 2) Mesa Redonda 20 “Democracia electoral rijosa y litigiosa en México: un caso, la paridad de género", en XVII Curso Anual de Apoyo Académico al Posgrado en Derecho de la UNAM aplicado a México, UNAM-Universidad Autónoma del Estado de Morelos-Instituto Morelense de Procesos Electorales y Participación Ciudadana (Impepac)-Tribunal Electoral del Estado de Morelos, Cuernavaca, 13 de noviembre de 2015, y 3) Mesa Redonda “La paridad de género en la reforma político-electoral", en 2o. Coloquio “Derechos de las mujeres: debates y asuntos pendientes", México, UNAM, Facultad de Derecho, 17 de noviembre de 2015.

2 Profesor en la Facultad de Derecho de la UNAM e investigador en el Instituto de Investigaciones Jurídicas de la UNAM, con reconocimientos Pride D y SNI III; correo electrónico: imer@unam.mx, twitter: @imerbflores. El autor agradece las invitaciones de María Marván, Luis Molina y Socorro Apresa; los comentarios de Eduardo Castellanos, Hugo Concha, Miguel Eraña, Luciana Gandini, María Marván y Santiago Nieto; así como las observaciones de Roberto Cabrera, Lisandro Devoto, Emilio Encarnación Brito, Gustavo Escalante, Balam Garcés, Fabiola Navarro y José Luis Ramos; y, en especial, a Roberto, quien me apoyó en la compilación de fuentes de información y en la realización de las tablas, así como en la identificación de una caricatura sobre el feminismo a la cual he recurrido en las exposiciones orales (disponible en http://www.collegehumor.com/post/7034561/what-gender-equality-would-really-look-like; página consultada el 16 de enero de 2016).
\end{abstract}


Esta obra forma parte del acervo de la Biblioteca Jurídica Virtual del Instituto de Investigaciones Jurídicas de la UNAM www.juridicas.unam.mx

[S]i la femme a le droit de monter sur l'échafaud, elle doit avoir également celui de monter à la tribune.

Olympe de Gouges, Déclaration des droits de la femme et de la citoyenne (1791)

I do not wish them [women] to have power over men; but over themselves. /

[W]omen ought to have representatives, instead of being arbitrarily governed without having any direct share allowed them in the deliberations of government.

Mary Wollstonecraft, $A$ Vindication of the Rights of Women (1792)

\section{Sumario}

I. A manera de introducción: “Feminismo-ta” más allá del velo de (mi) ignorancia

II. La lucha por la igualdad entre hombres y mujeres...

III. La paridad de género como punto de partida

IV. ¿La paridad de género como punto de llegada?

V. A modo de conclusión: de la democracia paritaria a la democracia societaria

\section{A MANERA DE INTRODUCCIÓN: “FEMINISMO-TA" MÁS ALLÁ DEL VELO DE (MI) IGNORANCIA}

Aclarar que no soy de sexo "mujer" ni de género "femenino" pero que sí estoy convencido de que es necesario luchar por la igualdad de derechos entre hombres y mujeres, así como acoger el "feminismo" y una perspectiva "feminista", me parece y hasta me resulta obligado. Es imperativo recordar que ambas palabras fueron acuñadas, una como sustantivo y la otra como adjetivo, alrededor de 1880-95, para referirse a la doctrina o al movimiento que aboga por la igualdad de derechos de las mujeres respecto a los hombres, así como a lo relativo a dicha doctrina o movimiento.

Así, a finales del siglo XIX y principios del XX la lucha se caracterizó por el reconocimiento de los derechos civiles y políticos de las mujeres, en general, y del derecho a votar y ser votadas, en particular. Como es sabido, al final de cuentas, obtendrían el voto tanto activo como pasivo en los Estados Unidos de América en 1920; en el Reino Unido en 1928, y en México -a nivel federal- hasta 1953. No obstante, en 
Esta obra forma parte del acervo de la Biblioteca Jurídica Virtual del Instituto de Investigaciones Jurídicas de la UNAM www.juridicas.unam.mx

la actualidad persisten infinidad de formas de discriminación en contra de las mujeres y hasta de opresión, subyugación, sumisión, las cuales nos han llevado a suscribir diferentes convenciones o tratados, tales como la Convención sobre la Eliminación de Todas las Formas de Discriminación Contra la Mujer (conocida como CEDAW, por sus siglas en inglés) y la Convención Interamericana para Prevenir, Sancionar y Erradicar la Violencia contra la Mujer, también denominada "Convención De Belem Do Pará", y adoptar políticas públicas tendientes a reducir la brecha entre hombres y mujeres.

Al respecto, me gustaría recordar el pensamiento de las tres autoras pioneras de lo que hoy conocemos como "feminismo", y que como tales son "proto-feministas", cuyas citas me han servido como epígrafes de este texto y que reflejan mi "feminismo" y mi postura "feminista".

La primera es Christine de Pizan o Pisan (1368-1430), castellanizada como Cristina de Pizán o Pisán, quien en su aclamada La cité de les dames / La ciudad de las damas (c.1405) afirma: “El más grande es aquel o aquella que tiene mayores méritos. La excelencia o la inferioridad de las gentes no reside en su cuerpo según el sexo, sino en la perfección de sus costumbres y virtudes". ${ }^{3} Y$ más adelante: "Si la costumbre fuera mandar a las niñas a la escuela y enseñarles las ciencias con método, como se hace con los niños, aprenderían y entenderían las dificultades y sutilezas de todas las artes y ciencias tan bien como ellos". ${ }^{4}$

La segunda es Marie Gouze (1748-1793), mejor conocida con el pseudónimo de Olympe de Gouges, quien en su célebre Déclaration des droits de la femme et de la citoyenne / Declaración de los derechos de la mujer y de la ciudadana (1791), en una clara paráfrasis de la Déclaration des droits de l'homme et du citoyene / Declaración de los derechos del hombre y del ciudadano (1789), asegura, de un lado, en el artículo VI:

La ley debe ser la expresión de la voluntad general; todas las Ciudadanas y Ciudadanos deben participar en su formación personalmente o por medio de sus representantes. Debe ser la misma para todos; todas las ciudadanas y todos los ciudadanos, por ser

${ }^{3}$ Cristina de Pizán, La ciudad de las damas, trad. de Marie-José Lemarchand, Madrid, Siruela, 2013, I, 9, p. 24.

4 Ibidem, I, 27, p. 63. 
Esta obra forma parte del acervo de la Biblioteca Jurídica Virtual del Instituto de Investigaciones Jurídicas de la UNAM www.juridicas.unam.mx

iguales a sus ojos, deben ser igualmente admisibles a todas las dignidades, puestos y empleos públicos, según sus capacidades y sin más distinción que la de sus virtudes y sus talentos.

$\mathrm{Y}$, del otro, en el numeral $\mathrm{X}$ : "Nadie debe ser molestado por sus opiniones incluso fundamentales; si la mujer tiene el derecho de subir al cadalso, debe tener también igualmente el de subir a la Tribuna con tal que sus manifestaciones no alteren el orden público establecido por la Ley". ${ }^{5}$

La tercera es Mary Wollstonecraft (1759-1797) —esposa de William Godwin y madre de Mary Shelley-, quien en su famosa $A$ Vindication of the Rights of Men / Una vindicación de los derechos de los hombres (1790) había advertido: "La virtud solamente puede florecer entre iguales". ${ }^{6} \mathrm{Y}$ en su no menos gloriosa secuela $A$ Vindication of the Rights of Woman / Una vindicación de los derechos de la mujer (1792) asevera, por un lado: "No deseo que tengan [las mujeres] poder sobre los hombres, sino sobre sí mismas". ${ }^{7} \mathrm{Y}$, por el otro: "[L]as mujeres deberían tener representantes, en vez de ser arbitrariamente gobernadas sin que se les permita ninguna participación directa en las deliberaciones de gobierno". ${ }^{8}$

Para concluir este apartado introductorio, me gustaría exhortar a adoptar a la John Rawls una especie de "velo de ignorancia", 9 para abordar la cuestión con

5 La Déclaration des droits de la femme et de la citoyenne está disponible en http://www./dhfrance.org/1791-DECLARATION-DES-DROITS-DE-LA/(página consultada el 16 de enero de 2016). Hay versión en

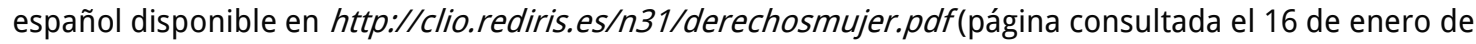
2016) (las cursivas son nuestras y corresponden a la cita que usamos como uno de los epígrafes de este texto).

${ }^{6}$ Wollstonecraft, Mary, A Vindication of the Rights of Men, in a Letter to the Right Honourable Edmund Burke; Occasioned by his Reflections on the Revolution in France, London, J. Johnson, 1790: "Virtue can only flourish amongst equals" (la traducción es nuestra).

7 Wollstonecraft, Mary, Vindicación de los derechos de la mujer, trad. de Marta Lois, Madrid, Istmo, 2005, IV, 34, p. 125 (título y publicación original: $A$ Vindication of the Rights of Woman: With Strictures of Political and Moral Subjects, London, J. Johnson, 1792).

8 Ibidem, IX, 22, p. 246.

${ }^{9}$ Véase Rawls, John, $A$ Theory of Justice, Cambridge, Massachusetts, Harvard University Press, 1971, pp. 136-142 (hay 2a. ed. rev., 1999, pp. 118-123) (hay versión en español: Teoría de la justicia, trad. de María 
Esta obra forma parte del acervo de la Biblioteca Jurídica Virtual del Instituto de Investigaciones Jurídicas de la UNAM www.juridicas.unam.mx

independencia de o -mejor dicho- sin prejuicios por ser "hombre o mujer" y "masculino/a o femenino/a". Me parece que una vez que nos encontramos más allá de dicho velo y no conocemos - o al menos hacemos como si no supiéramos- si somos hombre o mujer, masculino/a o femenino/a... estamos en una mejor posición para pronunciarnos de manera objetiva, y no de modo subjetivo sobre la paridad de género en cualquier materia, pero con especial referencia a la electoral.

\section{LA LUCHA POR LA IGUALDAD ENTRE HOMBRES Y MUJERES...}

Como se puede advertir no basta con reconocer el derecho a votar y a ser votadas de las mujeres sino que es $y$ ha sido necesario reconocer gradualmente diferentes principios e inclusive instrumentar distintas políticas públicas con miras a garantizar la igualdad entre hombres y mujeres. ${ }^{10}$ Desde la igualdad ante la ley hasta la igualdad en la ley, sin olvidar la prohibición de las diferentes formas de discriminación y la ampliación del principio de igualdad al requerir: primero, la igualdad de género; después, la equidad de género; $y$, ahora, la paridad de género.

En primera instancia, para consagrar la igualdad de género, en general, y en materia electoral, en particular, parece que basta con reconocer la igualdad formal o ante la ley entre hombres (bajo el eufemismo de 'varones') y mujeres, también conocida como

Dolores González, México, Fondo de Cultura Económica, 1979, pp. 163-169). Véase también Flores, Imer B., "El liberalismo igualitario de John Rawls", Cuestiones Constitucionales. Revista Mexicana de Derecho Constitucional, núm. 1, julio-diciembre de 1999, pp. 85-122; y “El problema de las candidaturas apartidistas, independientes o sin partido", en Ackerman, John M. (ed.), Nuevos escenarios del derecho electoral: los retos de la reforma de 2007-2008, México, UNAM, Instituto de Investigaciones Jurídicas, 2009, pp. 233-262.

10 Véase Flores, Imer B., “Igualdad, no discriminación (y políticas públicas): A propósito de la constitucionalidad o no del artículo 68 de la Ley General de Población", en Torre Martínez, Carlos de la (coord.), El derecho a la no discriminación, México, UNAM, Instituto de Investigaciones Jurídicas, 2006, pp. 263-306; “El derecho a la igualdad en el derecho comparado: el caso de México”, en $L a$ constitucionalización de las sociedades contemporáneas, Bogotá, Universidad de Santo Tomás, 2007, pp. 99-130; “El derecho a la igualdad en México”, Diritto e Procceso, años 2006-2009, junio de 2010, pp. 185216; y “Capítulo VII. Claroscuros de la jurisprudencia constitucional sobre derechos humanos: A propósito de un caso de (des)igualdad y proporcionalidad en México", en Vega Gómez, Juan (ed.), Temas selectos de derecho internacional privado y de derechos humanos. Estudios en homenaje a Sonia Rodríguez Jiménez, México, UNAM, 2014, pp. 151-183. 
Esta obra forma parte del acervo de la Biblioteca Jurídica Virtual del Instituto de Investigaciones Jurídicas de la UNAM www.juridicas.unam.mx

"isonomid", i. e. la misma norma, a partir de sendos decretos de reforma a la Constitución, publicados en el Diario Oficial de la Federación, el 17 de octubre de 1953 para ampliar la ciudadanía a las mujeres al explicitar en el artículo 34: “Son ciudadanos de la República los varones y las mujeres..."; y, el 31 de diciembre de 1974, para adicionar sin ambages en el artículo 40.: "El varón y la mujer son iguales ante la ley."

No obstante, como existían barreras culturales, las cuales podemos caracterizar como "machistas", para el ejercicio del derecho de las mujeres a votar, pero sobre todo para ser votadas, tales como la creencia de que la mujer haría lo que su marido le dijera o que de plano estaba y debería estar subordinada al hombre, fue necesario, en segundo lugar, fomentar una igualdad material o en la ley entre hombres y mujeres. Lo anterior, a partir del reconocimiento de las diferencias existentes entre ambos, al reconocer la igualdad de oportunidades y/o de respeto "isotimid", así como adoptar programas de acción afirmativa o positiva, y otras medidas tendientes a garantizar la equidad de género, las cuales son caracterizadas muchas veces como "cuotas". ${ }^{11}$

De tal suerte, en el ámbito electoral, el Código Federal de Instituciones y Procedimientos Electorales (Cofipe) estableció, en 1993, que los partidos políticos debían procurar promover una mayor participación de las mujeres en la vida política del país. Para 1996, se dispuso que en los estatutos partidistas se buscara que en las candidaturas tanto de mayoría relativa como de representación proporcional, no excedieran del 70\% para el mismo género. En 2002, se reformó el Cofipe para prescribir, con carácter obligatorio, un sistema de cuotas en el cual se exigía que los partidos políticos respetaran la proporción de 70\%-30\% de candidaturas para ambos géneros en los comicios federales; y para 2008 la proporción sería $60 \%-40 \%$.

No obstante, en la práctica, los partidos políticos incurrían en lo que se conoce como un "fraude a la ley", al hacer como que cumplían al postular como propietarias mujeres, quienes una vez electas tenían que "renunciar" a favor de sus suplentes hombres. Así, a partir de la resolución del SUP-JDC-12464/2011, mejor conocido como

\footnotetext{
11 Cuando las "cuotas" son rígidas o permanentes, tienden a ser consideradas como inconstitucionales, en cambio cuando son flexibles o temporales tienden a ser declaradas como constitucionales. Véase Dworkin, Ronald, A Matter of Principle, Cambridge, Massachusetts, Harvard University Press, 1985, pp. 293-331 (hay versión en español: Una cuestión de principios, trad. de Victoria de los Ángeles Boschiroli, Buenos Aires, Siglo XXI, 2012, pp. 363-407).
} 
Esta obra forma parte del acervo de la Biblioteca Jurídica Virtual del Instituto de Investigaciones Jurídicas de la UNAM www.juridicas.unam.mx

el caso de "Las Juanitas", y del SUP-JDC-12624/2011, otro caso estrechamente relacionado, la Sala Superior del Poder Judicial de la Federación estableció la obligatoriedad de cumplir las cuotas y la necesidad de que la fórmula de propietariosuplente sea del mismo género. En este orden de ideas, una vez que se adoptó el sistema de cuotas $70 \%-30 \%$, primero, y $60 \%-40 \%$, después, parece que el paso obligado era llegar a la paridad 50\%-50\%.

Antes de proseguir con el análisis crítico de la reforma a la Constitución general de la República, misma que analizaremos en el próximo apartado, debemos recordar que con anterioridad a la misma:

1) A nivel internacional, Francia fue la primera en promulgar el 6 de junio de 2000 la "Loi du parite" para favorecer el acceso igualitario de hombres y mujeres a mandatos electorales y funciones electivas, y fue seguida por Bélgica (2002), España (2007), Senegal (2010) y Túnez (2011). ${ }^{12}$

2) A nivel regional, en América Latina, los dos primeros países en incorporar la paridad de género fueron Bolivia y Ecuador, en 2008, seguidos por Costa Rica (2009), Honduras, Nicaragua y Panamá (2012). ${ }^{13}$

3) A nivel subnacional, el Estado de Guerrero estableció, en 2007, para la elección de diputados al congreso estatal y ayuntamientos, a partir del proceso de 2008 y para los subsecuentes, la paridad de género. ${ }^{14}$

12 Véase Peña Molina, Blanca Olivia, “La paridad de género: eje de la reforma político-electoral en México”, Revista Mexicana de Estudios Electorales, núm. 14, 2014, pp. 31-74, y, en especial, 35-36, disponible en http://www.somee.org.mx/rmestudioselectorales/index.php/RMEstudiosElectorales/article/view/135 (página consultada el 16 de enero de 2016).

13 Véase Archenti, Nelida y Tula, María Inés, “Cambios normativos y equidad de género. De las cuotas a la paridad en América Latina: los casos de Bolivia y Ecuador", América Latina Hoy. Revista de Ciencias Sociales, vol. 66, abril de 2014, pp. 47-68. Véase también Peña Molina, "La paridad de género...", cit. en la nota 10, pp. 36 y 37. Cabe mencionar que en todos los casos aplican la paridad de género en las candidaturas a su Asamblea o Congreso Nacional, con la única excepción de Panamá, en donde se aplica solamente en las elecciones internas o primarias de los partidos políticos.

14 Véase Eugenio Alcaraz, Alma Delia, “Paridad de género. Avances, balance en el proceso electoral 2008 y retos", Altamirano. Revista del H. Congreso del Estado de Guerrero, sexta época, año 9, núm. 38, enero de 2010, pp. 21-36. 
Esta obra forma parte del acervo de la Biblioteca Jurídica Virtual del Instituto de Investigaciones Jurídicas de la UNAM www.juridicas.unam.mx

\section{LA PARIDAD DE GÉNERO COMO PUNTO DE PARTIDA}

La controvertida reforma a la Constitución general de la República, publicada en el Diario Oficial de la Federación del 10 de febrero del 2014, tiene entre sus aspectos la inclusión del principio de la paridad de género / entre los géneros en nuestro ordenamiento jurídico-nacional y con rango de constitucional, pero aparece limitado a la postulación de candidaturas a legisladores federales y locales. Como veremos a continuación se trata de un "punto de partida" y no necesariamente de un "punto de llegada".

Así, el segundo párrafo de la fracción I del artículo 41 establece:

Los partidos políticos tienen como fin promover la participación del pueblo en la vida democrática, contribuir a la integración de los órganos de representación política y como organizaciones de ciudadanos, hacer posible el acceso de éstos al ejercicio del poder público, de acuerdo con los programas, principios e ideas que postulan y mediante el sufragio universal, libre, secreto y directo, así como las reglas para garantizar la paridad entre los géneros, en candidaturas a legisladores federales y locales. Sólo los ciudadanos podrán formar partidos políticos y afiliarse libre e individualmente a ellos; por tanto, quedan prohibidas la intervención de organizaciones gremiales o con objeto social diferente en la creación de partidos y cualquier forma de afiliación corporativa.

Como se puede advertir, la "paridad de género" nace como una obligación de los partidos políticos, los cuales deben "garantizar la paridad entre los géneros, en candidaturas a legisladores federales y locales"; y, en consecuencia, postular a un 50\% de hombres y un $50 \%$ de mujeres, ya sea para senadores, diputados federales y diputados locales, lo cual constituye un punto de partida y no necesariamente uno de llegada. ${ }^{15}$

\footnotetext{
15 Me permito aclarar que la "paridad de género" como principio constitucional constituye un "punto de partida" al exigir la paridad en la postulación de candidaturas y no un "punto de llegada" al requerir la paridad en el resultado material de la representación política, la cual está y debe estar sujeta a otros principios, i. e. tanto al principio de legalidad como al principio democrático de voluntad popular o de voto popular y directo. De igual forma, es posible distinguir entre "paridad vertical", la cual se cumple al intercalar hombres y mujeres o viceversa en las listas partidistas; $y$, "paridad horizontal", la cual se cumple al postular una mitad de fórmulas de hombres y otra mitad de mujeres en la totalidad de un mismo cargo o puesto de elección popular.
} 
Esta obra forma parte del acervo de la Biblioteca Jurídica Virtual del Instituto de Investigaciones Jurídicas de la UNAM www.juridicas.unam.mx

Al respecto, en México, la primera prueba de fuego para la paridad de género fueron las elecciones federales intermedias y locales concurrentes de 2015, en las cuales se tenían que elegir a los diputados tanto al Congreso de la Unión como a los congresos locales, conforme a los principios de votación mayoritaria relativa y de representación proporcional, pero no a los senadores, los cuales coinciden con las elecciones federales presidenciales. ${ }^{16}$

Para cumplir a cabalidad con la obligación genérica de garantizar la paridad de género, al menos como punto de partida, y para evitar lo que se conoce como "fraude a la ley" (y peor aún cuando la ley en cuestión es la propia "Constitución"), sobre todo a partir de la experiencia del caso de "Las Juanitas" y de los demás relacionados, los partidos políticos debían cumplir con tres obligaciones específicas:

1) Postular en sus candidaturas a $50 \%$ de hombres y $50 \%$ de mujeres;

2) Presentar fórmulas en las que tanto propietario/a como suplente sean del mismo sexo; y

3) Alternar, en sus listas de partidos, los nombres de hombres y mujeres o viceversa.

\section{En el ámbito federal}

Por una parte, a nivel federal, para la elección de los 300 diputados electos según el principio de votación mayoritaria relativa, mediante el sistema de distritos electorales uninominales, debían postular 50\% de hombres y 50\% de mujeres, así como presentar fórmulas en las cuales tanto el propietario/a como el suplente fueran del mismo sexo, y en consecuencia un máximo de 150 fórmulas con hombres y 150 con mujeres. Y, para los 200 diputados electos según el principio de representación proporcional, mediante el sistema de listas regionales, votadas en circunscripciones plurinominales, debían alternar los nombres de hombres y mujeres o viceversa.

\footnotetext{
16 Si bien no es estrictamente necesaria una reforma a la Constitución General de la República para instrumentar la paridad de género en el Senado, pues bastaría con que los partidos políticos postularan la mitad de fórmulas con hombres y la otra con mujeres, así como intercalarán en sus listas de representación proporcional los nombres de hombres y mujeres. En lo personal, me inclino a pensar que sí es conveniente hacer una reforma en la materia. Véase Flores, Imer B., “El problema de la (eventual) reforma del Senado en México", Revista Mexicana de Derecho Electoral, vol. 1, núm. 1, enero-junio de 2012, pp. 27-55.
} 
Esta obra forma parte del acervo de la Biblioteca Jurídica Virtual del Instituto de Investigaciones Jurídicas de la UNAM www.juridicas.unam.mx

DOI: http://dx.doi.org/10.22201/iij_24487910e.2016.9.10095

Los resultados de la elección intermedia de 2015 de diputados al Congreso de la Unión están resumidos en la Tabla 1, en tanto que los senadores en la Tabla 2:

Tabla 1

Representación por género, partido y principio en la Cámara de Diputados en

México (a partir de los resultados de la elección federal intermedia de 2015)

\begin{tabular}{|c|c|c|c|c|c|c|c|c|c|}
\hline \multirow[t]{2}{*}{$\begin{array}{l}\text { Partido } \\
\text { político }\end{array}$} & \multicolumn{3}{|c|}{ Mayoría relativa } & \multicolumn{3}{|c|}{$\begin{array}{l}\text { Representación } \\
\text { proporcional }\end{array}$} & \multicolumn{3}{|c|}{ Totales } \\
\hline & $M$ & $H$ & Total & $M$ & $H$ & Total & $M$ & $H$ & $\begin{array}{l}\text { Tot } \\
\text { al }\end{array}$ \\
\hline & 65 & 90 & 155 & 23 & 25 & 48 & 88 & 115 & 203 \\
\hline & $41.93 \%$ & $\begin{array}{l}58.06 \\
\%\end{array}$ & $\begin{array}{l}100 \\
\%\end{array}$ & $\begin{array}{l}47.91 \\
\%\end{array}$ & $\begin{array}{l}52.08 \\
\%\end{array}$ & $\begin{array}{l}100 \\
\%\end{array}$ & $\begin{array}{l}43.34 \\
\%\end{array}$ & $\begin{array}{l}56.65 \\
\%\end{array}$ & $\begin{array}{l}100 \\
\%\end{array}$ \\
\hline & 22 & 34 & 56 & 25 & 28 & 53 & 47 & 62 & 109 \\
\hline & $39.28 \%$ & $\begin{array}{l}60.71 \\
\%\end{array}$ & $\begin{array}{l}100 \\
\%\end{array}$ & $\begin{array}{l}47.16 \\
\%\end{array}$ & $\begin{array}{l}52.83 \\
\%\end{array}$ & $\begin{array}{l}100 \\
\%\end{array}$ & $\begin{array}{l}43.11 \\
\%\end{array}$ & $\begin{array}{l}56.88 \\
\%\end{array}$ & $\begin{array}{l}100 \\
\%\end{array}$ \\
\hline & 10 & 24 & 34 & 13 & 14 & 27 & 23 & 38 & 61 \\
\hline & $29.41 \%$ & $\begin{array}{l}70.58 \\
\%\end{array}$ & $\begin{array}{l}100 \\
\%\end{array}$ & $\begin{array}{l}48.14 \\
\%\end{array}$ & $\begin{array}{l}51.85 \\
\%\end{array}$ & $\begin{array}{l}100 \\
\%\end{array}$ & $\begin{array}{l}37.70 \\
\%\end{array}$ & $\begin{array}{l}62.29 \\
\%\end{array}$ & $\begin{array}{l}100 \\
\%\end{array}$ \\
\hline & 8 & 21 & 29 & 9 & 9 & 18 & 17 & 30 & 47 \\
\hline & $27.58 \%$ & $\begin{array}{l}72.41 \\
\%\end{array}$ & $\begin{array}{l}100 \\
\%\end{array}$ & $50 \%$ & $50 \%$ & $\begin{array}{l}100 \\
\%\end{array}$ & $\begin{array}{l}36.17 \\
\%\end{array}$ & $\begin{array}{l}63.82 \\
\%\end{array}$ & $\begin{array}{l}100 \\
\%\end{array}$ \\
\hline & 8 & 6 & 14 & 10 & 11 & 21 & 18 & 17 & 35 \\
\hline & $57.14 \%$ & $\begin{array}{l}42.85 \\
\%\end{array}$ & $\begin{array}{l}100 \\
\%\end{array}$ & $\begin{array}{l}47.61 \\
\%\end{array}$ & $\begin{array}{l}52.38 \\
\%\end{array}$ & $\begin{array}{l}100 \\
\%\end{array}$ & $\begin{array}{l}51.42 \\
\%\end{array}$ & $\begin{array}{l}48.57 \\
\%\end{array}$ & $\begin{array}{l}100 \\
\%\end{array}$ \\
\hline & 4 & 6 & 10 & 7 & 8 & 15 & 11 & 14 & 25 \\
\hline CMOUADANO & $40 \%$ & $60 \%$ & $\begin{array}{l}100 \\
\%\end{array}$ & $\begin{array}{l}46.66 \\
\%\end{array}$ & $\begin{array}{l}53.33 \\
\%\end{array}$ & $\begin{array}{l}100 \\
\%\end{array}$ & $44 \%$ & $56 \%$ & $\begin{array}{l}100 \\
\%\end{array}$ \\
\hline
\end{tabular}


Esta obra forma parte del acervo de la Biblioteca Jurídica Virtual del Instituto de Investigaciones Jurídicas de la UNAM www.juridicas.unam.mx https://biblio.juridicas.unam.mx/bjv https://revistas.juridicas.unam.mx/

DOl: http://dx.doi.org/10.22201/ijj.24487910e_2016.9.10095

\begin{tabular}{|c|c|c|c|c|c|c|c|c|c|}
\hline & 0 & 1 & 1 & 5 & 5 & 10 & 5 & 6 & 11 \\
\hline alianzag & $0 \%$ & $100 \%$ & $\begin{array}{l}100 \\
\%\end{array}$ & $50 \%$ & $50 \%$ & $\begin{array}{l}100 \\
\%\end{array}$ & $\begin{array}{l}45.45 \\
\%\end{array}$ & $\begin{array}{l}54.54 \\
\%\end{array}$ & $\begin{array}{l}100 \\
\%\end{array}$ \\
\hline & 0 & 0 & 0 & 3 & 5 & 8 & 3 & 5 & 8 \\
\hline $\begin{array}{c}\text { encuentro } \\
\text { social }\end{array}$ & --- & --- & --- & $37.5 \%$ & $62.5 \%$ & $\begin{array}{l}100 \\
\%\end{array}$ & $37.5 \%$ & $\begin{array}{l}62.5 \\
\%\end{array}$ & $\begin{array}{l}100 \\
\%\end{array}$ \\
\hline & 0 & 1 & 1 & 0 & 0 & 0 & 0 & 1 & 1 \\
\hline & $0 \%$ & $100 \%$ & $\begin{array}{l}100 \\
\%\end{array}$ & --- & --- & --- & $0 \%$ & $100 \%$ & $\begin{array}{l}100 \\
\%\end{array}$ \\
\hline & 117 & 183 & 300 & 95 & 105 & 200 & 212 & 288 & 500 \\
\hline Total & $39.13 \%$ & $\begin{array}{l}60.86 \\
\%\end{array}$ & $\begin{array}{l}100 \\
\%\end{array}$ & $47.5 \%$ & $52.5 \%$ & $\begin{array}{l}100 \\
\%\end{array}$ & $42.4 \%$ & $\begin{array}{l}57.6 \\
\%\end{array}$ & $\begin{array}{l}100 \\
\%\end{array}$ \\
\hline
\end{tabular}

FUENTE: Elaboración propia con datos de la página de la Cámara de Diputados, disponible en http://sitl.diputados.gob.mx/LXIII_leg/info_diputados.php (página consultada el 16 de enero de 2016).

Tabla 2

Representación por género y partido en la Cámara de Senadores en México (a partir de los resultados de la elección federal de 2012)

\begin{tabular}{|l|l|l|l|l|l|l|}
\hline Partido & \multicolumn{2}{|l|}{ Mujeres } & \multicolumn{2}{l|}{ Hombres } & \multicolumn{2}{l|}{ Total } \\
\hline $\mathbf{R}$ & 19 & $35.18 \%$ & 35 & $64.81 \%$ & 54 & $42.2 \%$ \\
\hline & 13 & $34.21 \%$ & 25 & $65.78 \%$ & 38 & $29.7 \%$ \\
\hline & 5 & $23.80 \%$ & 16 & $76.19 \%$ & 21 & $16.4 \%$ \\
\hline
\end{tabular}


Esta obra forma parte del acervo de la Biblioteca Jurídica Virtual del Instituto de Investigaciones Jurídicas de la UNAM www.juridicas.unam.mx

\begin{tabular}{|c|c|c|c|c|c|c|}
\hline VER & 2 & $28.57 \%$ & 5 & $71.42 \%$ & 7 & $5.5 \%$ \\
\hline $\begin{array}{|ll|}0 & 4 \\
17 & 7 \\
\end{array}$ & 3 & $50 \%$ & 3 & $50 \%$ & 6 & $4.7 \%$ \\
\hline $\begin{array}{l}\text { Sin grupo } \\
\text { parlamentario }\end{array}$ & 2 & $100 \%$ & 0 & --- & 2 & $1.6 \%$ \\
\hline Total & 44 & $34.37 \%$ & 84 & $65.62 \%$ & 128 & $100 \%$ \\
\hline
\end{tabular}

FUENTE: Elaboración propia con datos de la página de la Cámara de Senadores: http://www.senado.gob.mx/index.php (página consultada el 16 de enero de 2016).

De entrada, como se puede notar, el total de diputados es 500 , conforme al principio de mayoría relativa 300 (60\%) y al de representación proporcional 200 (40\%). De un lado, de los 300 de mayoría relativa fueron electos: 183 (60.9\%) hombres y 117 (39.1\%) mujeres; $y$, del otro, de los 200 de representación proporcional: 105 (52.5\%) hombres y 95 (47.5\%) mujeres. Lo cual arroja un gran total para la Legislatura LXIII de $288(57.6 \%)$ hombres y 212 (42.4\%) mujeres diputados; y constituye sin duda alguna la mayor representación histórica de mujeres en el Congreso mexicano, al sobrepasar el umbral de $40 \%{ }^{17}$

17 Por lo tanto, el logro es parcial, ya que en la cámara alta, i. e. el Senado de la República, hay casi dos tercios de hombres y poco más de uno de mujeres, i. e. 84 (65.6\%) hombres y 44 (34.3\%) mujeres. Al agregar los datos, el resultado es 372 (59.2\%) hombres y 256 (40.8\%) mujeres. Empero, si 42.4\% fuera el resultado para ambas cámaras del Congreso de la Unión, México sería el 7o. país del mundo con el mayor número de mujeres en el Parlamento, por debajo de Senegal con $42.7 \%$ y por encima no solamente de Sudáfrica con $41.9 \%$ y de Ecuador con $41.6 \%$, sino además de dos países escandinavos tales como Finlandia con $41.5 \%$ e Islandia con $41.3 \%$. Al respecto, solamente Ruanda y Bolivia tienen más mujeres que hombres con $63.8 \%$ y $53.1 \%$, respectivamente. Seguidos por Cuba con $48.9 \%$, Seychelles con $43.8 \%$ y Suecia con $43.6 \%$. Como se puede apreciar, actualmente, entre los 10 primeros lugares están: 4 países africanos (Ruanda 10., las islas Seychelles 40., Senegal 6o. y Sudáfrica 7o.); 3 países latinoamericanos (Bolivia 20., Cuba 3o. y Ecuador 8o.); y 3 países escandinavos-nórdicos (Suecia 5o., Finlandia 9o., e Islandia 
Esta obra forma parte del acervo de la Biblioteca Jurídica Virtual del Instituto de Investigaciones Jurídicas de la UNAM www.juridicas.unam.mx

No obstante, como se puede apreciar, el problema con este arreglo, el cual requiere alternar hombres y mujeres o viceversa, en las cinco listas regionales, es que en la práctica los partidos políticos comienzan con hombres seguidos de mujeres. Con lo cual, en lugar de que fueran electos 100 (50\%) hombres y 100 (50\%) mujeres, resultó que a final de cuentas fueron electos 105 (52.5\%) hombres y 95 (47.5\%) mujeres, i. e. un diferencial de +11 hombres/mujeres. ${ }^{18} \mathrm{Si}$ bien, a partir de los resultados, los partidos Verde y Nueva Alianza mantuvieron una paridad entre hombres-mujeres de 99 y 5-5, respectivamente, no fue el caso para los demás partidos. Así, los partidos de la Revolución Democrática, Movimiento Ciudadano y Morena obtuvieron cada uno un hombre de más, i. e. 14-13, 8-7, y 11-10, respectivamente; tanto el Revolucionario Institucional como Encuentro Social dos hombres de más, i. e. 25-23, y 5-3, respectivamente; y Acción Nacional tres hombres de más, i. e. 28-25, conforme a la misma Tabla 1.

\section{En el ámbito local}

Por otra parte, para la elección de los diputados a los congresos locales son aplicables, como veremos, mutatis mutandis los mismos criterios. Sin embargo, antes de proseguir, habría que abrir un breve paréntesis para discutir la ampliación del principio de paridad de género al ámbito municipal, pues como habíamos visto parecía estar reservada nada más a los legisladores tanto federales como locales. ${ }^{19}$

\section{A. El caso de los ayuntamientos}

Por un lado, en el caso de los ayuntamientos, cabe recordar que al resolver el SDF-JRC17/2015 y sus acumulados 18 y 19/2015 la Sala Regional, con sede en el Distrito Federal, confirmó la resolución del Tribunal Electoral del Estado de Morelos en los expedientes TEE/RAP/012/2015-1 y sus acumulados 014 y 015/2015-1, misma que

100.), la información está disponible en https://agenda.weforum.org/2015/09/countries-most-women-inparliament/?utm_content=bufferocdd3\&utm_medium=social\&utm_source=facebook.com\&utm_campaign= buffer (página consultada el 16 de enero de 2016).

18 Dado que falta designar a un/a diputado federal conforme al principio de representación proporcional, dicho diferencial puede ser solamente de +10 hombres/mujeres, pero puede darse el caso de que llegue a ser de +12 hombres/mujeres.

19 Véase Coello Cetina, Rafael, “Aplicación del principio de paridad de género en el ámbito electoral municipal", Examen, año XXIII, núm. 228, marzo de 2014, pp. 44-49. 
Esta obra forma parte del acervo de la Biblioteca Jurídica Virtual del Instituto de Investigaciones Jurídicas de la UNAM www.juridicas.unam.mx

convalidó el acuerdo del IMPEPAC/CEE/0005/2015, mediante el cual se estableció el criterio para la aplicación de la paridad de género en la integración de las planillas de candidatos a presidente municipal y síndico propietario, así como sus respectivos suplentes.

Dicho acuerdo, a partir de una interpretación extensiva e inclusive de una integración analógica a pari, amplió el alcance del artículo 41 constitucional, para incluir el caso de los ayuntamientos a la par de los congresos tanto federal como locales, y establecer que en el total de municipios del Estado de Morelos se debían postular en la mitad de ellos fórmulas de candidatos tanto propietarios como suplentes del mismo sexo, i. e. de los 33 municipios, hasta 17 fórmulas de un sexo y 16 del sexo opuesto, así como alternar en las planillas los nombres de hombres y mujeres o viceversa. Con lo anterior se consagró no solamente la "paridad vertical" al interior de cada planilla para el ayuntamiento en cuestión, sino además la "paridad horizontal" en el total de las planillas postuladas por un mismo partido en la entidad en cuestión.

El precedente sería confirmado por la Sala Superior al resolver el expediente SUPREC-46/2015, en el caso del mismo Estado de Morelos, por unanimidad de 5 votos; y reiterado al resolver los expedientes:

1) SUP-REC-90/2015 y su acumulado 91/2015, para el caso del Estado de Sonora, con una mayoría de 4 votos contra 2, al revocar la sentencia emitida por la Sala Regional, con sede en Guadalajara, Jalisco, del Tribunal Electoral del Poder Judicial de la Federación, en el juicio para la protección de los derechos político-electorales del ciudadano SG-JDC-11138/2015, y confirmar el acuerdo IEEPC/CG/61/15 emitido por el Consejo General del Instituto Estatal Electoral y de Participación Ciudadana del Estado de Sonora, mediante el cual aprobó el criterio de aplicación de la paridad y alternancia de género en las solicitudes de registro de candidaturas a diputaciones por el principio de mayoría relativa, así como de representación proporcional, y de las planillas de ayuntamientos para la elección ordinaria 2014-2015; y

2) SUP-REC-294/2015, para el caso del Estado de Chiapas, por unanimidad de seis votos, al revocar el acuerdo IEPC/CG/A-071/2015, mediante el cual el Consejo General del Instituto de Elecciones y Participación Ciudadana del Estado de Chiapas aprobó, entre otras cuestiones, las solicitudes de registro de candidaturas a diputaciones del Congreso estatal por el principio de mayoría relativa, así como de 
Esta obra forma parte del acervo de la Biblioteca Jurídica Virtual del Instituto de Investigaciones Jurídicas de la UNAM www.juridicas.unam.mx

miembros de los ayuntamientos de la entidad; ordenar al Consejo General del Instituto de Elecciones y Participación Ciudadana del Estado de Chiapas que realice las actividades ordenadas en la presente resolución; y vincular a los partidos políticos y coaliciones que participan en el proceso electoral local en Chiapas a su cumplimiento.

\section{B. El caso de los congresos}

Por el otro, en el caso de los diputados a los congresos locales, los partidos políticos debían cumplir y cumplieron con los tres criterios para garantizar la paridad de género como punto de partida. No obstante, en la asignación de curules conforme al principio de representación proporcional, en los casos de los Estados tanto de Yucatán como de Morelos, los respectivos consejos generales, así como la Sala Regional con sede en Xalapa, Veracruz, para el primero, y el Tribunal Electoral del Estado de Morelos, para el segundo, trataron de aplicar en dicha asignación el principio de paridad de género como punto de llegada, pero la Sala Superior reiteró que dicho principio es y debe ser entendido como punto de partida.

\section{a. Yucatán}

La Sala Superior en el expediente SUP-REC-575/2015 y su acumulado 596/2015, con una mayoría de 4 votos contra 1, resolvió: revocar la sentencia dictada por la Sala Regional con sede en Xalapa, Veracruz, del Tribunal Electoral del Poder Judicial de la Federación, en los expedientes SX-JDC-802/2015 y sus acumulados 803/2015, 804/2015 y 805/2015; confirmar no sólo la sentencia dictada por el Tribunal Electoral del Estado de Yucatán en el JDC-06/2015 y sus acumulados, sino también la asignación realizada por dicho tribunal en tal sentencia; y ordenar al Consejo General del Instituto Electoral y de Participación Ciudadana de Yucatán que de forma inmediata expida a los ciudadanos y ciudadanas las constancias correspondientes, e informe sobre el cumplimiento dado al presente fallo dentro de las veinticuatro horas a partir de que ello ocurra.

Al respecto, en el Estado de Yucatán se eligen 23 diputados al Congreso del Estado, 13 conforme al principio de mayoría relativa y los 10 restantes al de representación proporcional, a partir de las listas de partidos. Sin embargo, en la entidad, cada lista partidista resulta de intercalar a 5 de la lista preliminar, en la cual alternan los nombres de hombres y mujeres, y 5 de la segunda lista, la cual corresponde a los 
Esta obra forma parte del acervo de la Biblioteca Jurídica Virtual del Instituto de Investigaciones Jurídicas de la UNAM www.juridicas.unam.mx

mejores segundos lugares en orden descendente, pero sin conocer de antemano si se trata de hombres o mujeres. ${ }^{20}$

Dados los resultados, al PAN le correspondían 6 diputados por representación proporcional, en tanto que al PRD, PVEM, PANAL y MORENA tan sólo 1 diputado a cada uno. Conviene señalar que de los 4 últimos, solamente 1 era mujer $(\mathrm{H}-\mathrm{H}-\mathrm{H}-\mathrm{M})$, y que en el caso de los 6 del PAN, con una estricta paridad de género, ya no en la salida sino en la llegada, deberían ser 3 hombres y 3 mujeres. Ahora bien, para el caso del PAN, al intercalar la lista preliminar (H-M-H-M-H) y la segunda lista (H-H-H-M-M) resultan 6 hombres y 4 mujeres (H-H-M-H-H-H-M-M-H-M), y peor aún en los seis primeros 5 hombres y tan sólo 1 mujer ( $\mathrm{H}-\mathrm{H}-\mathrm{M}-\mathrm{H}-\mathrm{H}-\mathrm{H})$, lo cual habría dado como resultado que de los 10 diputados electos conforme al principio de representación proporcional en la entidad fueran 8 hombres y tan sólo 2 mujeres (H-H-M-H-H-H + H-H-H-M).

Sin embargo, como este resultado no convenció al Consejo General del Instituto Electoral y de Participación Ciudadana de Yucatán, optaron por reacomodar la prelación de la segunda lista para el caso de la lista del PAN, para que en lugar de 5 hombres y 1 mujer, quedarán 2 hombres y 4 mujeres, para que el resultado final fuera de 5 hombres y 5 mujeres. El contraste entre "Lo que deberían haber hecho" y "Lo que hicieron" se puede apreciar en la Tabla 3, pero a grandes rasgos, el 20. y 40. lugares correspondientes a hombres se convirtieron en el 80. y 100., y viceversa el 80. y el 100. lugar correspondientes a mujeres se convirtieron en el 20. y 4o. De igual forma, acabaron por excluir al 6o. lugar, el cual le correspondía a un hombre, para incluir en el mismo a una mujer, la cual no había quedado entre los cinco mejores segundos lugares, cuando además había todavía otra mujer en la lista preliminar, en el 7o. lugar.

Tabla 3.

Integración de la lista final del PAN en Yucatán (comparativo a partir

de los resultados de la elección local de 2015)

\begin{tabular}{|l|l|l|l|}
\hline Núm. & Lo que deberían haber hecho & Origen & Lo que hicieron \\
\hline
\end{tabular}

\footnotetext{
20 Este arreglo no rompe ni debe romper necesariamente ex ante con la paridad de género, al depender de los resultados del día de la votación, los cuales son contingentes, y que como tales pueden romper o no ex post con dicha paridad. Aunque dado el estado de cosas es muy probable que la rompan.
} 
Esta obra forma parte del acervo de la Biblioteca Jurídica Virtual del Instituto de Investigaciones Jurídicas de la UNAM www.juridicas.unam.mx

\begin{tabular}{|l|l|l|l|}
\hline 1. & Hombre (RPA) & $\begin{array}{l}\text { Lista } \\
\text { preliminar }\end{array}$ & Hombre (RPA) \\
\hline 2. & Hombre (RMRB) & Segunda lista & Mujer (CNVC) \\
\hline 3. & Mujer (MBZP) & $\begin{array}{l}\text { Lista } \\
\text { preliminar }\end{array}$ & Mujer (MBZP) \\
\hline 4. & Hombre (MJAC) & Segunda lista & Mujer (PPAS) \\
\hline 5. & Hombre (IDCG) & $\begin{array}{l}\text { Lista } \\
\text { preliminar }\end{array}$ & Hombre (JDCG) \\
\hline 6. & Hombre (RGMM) & Segunda lista & Mujer (YGCC) \\
\hline 7. & Mujer (NMM) & $\begin{array}{l}\text { Lista } \\
\text { preliminar }\end{array}$ & Mujer (NMM) \\
\hline 8. & Mujer (CNVC) & Segunda lista & Hombre (RMRB) \\
\hline 9. & Hombre (REGC) & $\begin{array}{l}\text { Lista } \\
\text { preliminar }\end{array}$ & Hombre (REGC) \\
\hline 10. & Mujer (PPAS) & Segunda lista & Hombre (MJAC) \\
\hline
\end{tabular}

FUENTE: Elaboración propia con los datos contenidos en el expediente SUP-REC-575/2015 y su acumulado 596/2015.

A partir de la lista final del PAN, el Consejo Electoral procedió a la asignación de los 10 diputados conforme al principio de representación proporcional, pero la misma fue revocada por el Tribunal Electoral estatal, y su asignación por la Sala Regional con sede en Xalapa, y la de ésta a su vez por la Sala Superior. El contraste entre "Lo que habían hecho" tanto el Consejo General como la Sala Regional, y a final de cuentas "Lo que resolvieron", a partir de la resolución de la Sala Superior, la cual al revocar la resolución de la Sala Regional, acaba por confirmar la del Tribunal Electoral estatal, se puede apreciar en la Tabla 4, pero básicamente los primeros entendieron a la paridad de género como punto de llegada para quedar 5 hombres y 5 mujeres, en tanto que los segundos como punto de partida para quedar 8 hombres y 2 mujeres.

Tabla 4

Asignación de diputados por representación proporcional en Yucatán

(comparativo a partir de los resultados de la elección local de 2015) 
Esta obra forma parte del acervo de la Biblioteca Jurídica Virtual del Instituto de Investigaciones Jurídicas de la UNAM www.juridicas.unam.mx

\begin{tabular}{|l|l|l|l|}
\hline Núm. & Lo que habían hecho & $\begin{array}{l}\text { Partido } \\
\text { político }\end{array}$ & Lo que resolvieron \\
\hline 1. & Hombre (RPA) & PAN & Hombre (RPA) \\
\hline 2. & Mujer (CNVC) & PAN & Hombre (RMRB) \\
\hline 3. & Mujer (MBZP) & PAN & Mujer (MBZP) \\
\hline 4. & Mujer (PPAS) & PAN & Hombre (MJAC) \\
\hline 5. & Hombre (IDCG) & PAN & Hombre (JDCG) \\
\hline 6. & Mujer (YGCC) & PAN & Hombre (RGMM) \\
\hline 7. & Hombre (DABZ) & PRD & Hombre (DABZ) \\
\hline 8. & Hombre (EGFB) & PVEM & Hombre (EGFB) \\
\hline 9. & Hombre (MABN) & PANAL & Hombre (MABN) \\
\hline 10. & Mujer (IYVM) & Morena & Mujer (JYMM) \\
\hline
\end{tabular}

FUENTE: Elaboración propia con los datos contenidos en el expediente SUP-REC575/2015 y su acumulado 596/2015.

\section{b. Morelos}

La Sala Superior en el expediente SUP-JRC-680/2015 y sus acumulados 681/2015, 682/2015 y 683/2015, así como SUP-JDC-1263/2015, 1264/2015, 1265/2015, 1266/2015, $1267 / 2015,1268 / 2015,1269 / 2015,1276 / 2015,1277 / 2015$ y 1278/2015, y el diverso SUP-JRC-680/2015, por unanimidad de 6 votos, resolvió: revocar las sentencias dictadas por el Tribunal Electoral del Estado de Morelos, así como el acuerdo IMPEPAC/CEE/177/2015, emitido por el Consejo Estatal Electoral del Estado de Morelos por el que aprobó la asignación de las curules por el principio de representación proporcional, y -en consecuencia- las constancias de asignación de las diputaciones por el principio de representación proporcional al Congreso del Estado de Morelos; y ordenar al Consejo Estatal Electoral de Instituto Morelense de Procesos Electorales y Participación Ciudadana que en el plazo de tres días expida y entregue las constancias de asignación como diputadas y diputados por el principio de representación a favor de quienes corresponda en términos de esta ejecutoria, previa revisión del 
Esta obra forma parte del acervo de la Biblioteca Jurídica Virtual del Instituto de Investigaciones Jurídicas de la UNAM www.juridicas.unam.mx

cumplimiento de los requisitos de elegibilidad, debiendo informar a la Sala Superior dentro de las veinticuatro horas siguientes al cumplimiento.

En cuanto al Estado de Morelos se eligen 30 diputados al Congreso del Estado: 18 conforme al principio de mayoría relativa y los 12 restantes al de representación proporcional, a partir de las listas de partidos. De los 18 de mayoría relativa, dados los resultados le correspondieron 15 a hombres y 3 a mujeres; y de los 12 de representación proporcional, solamente a 2 de los 10 partidos, les correspondían dos diputaciones de representación proporcional, con lo cual una tendría que ser para cada género, y a los otros 8 una a cada uno, a partir de lo previsto en su lista.

Es conveniente realizar un par de aclaraciones: 1) todos los partidos, menos uno, comenzaron sus listas con hombres; y 2) uno de los partidos que comenzaron sus listas con hombres, no incluyó mujeres, pues calculaba alcanzar solamente una diputación por este mecanismo, y por esa razón se le hacía un requerimiento para señalar ex post el nombre de la mujer a la que le correspondería la diputación. De esta forma, dentro de los 10 primeros lugares había 9 hombres y 1 mujer (H-H-H-H-H-H-H-H-M-H) y los 2 restantes serían para mujeres (M-M), para totalizar 9 hombres y 3 mujeres conforme al principio de representación proporcional ( $\mathrm{H}-\mathrm{H}-\mathrm{H}-\mathrm{H}-\mathrm{H}-\mathrm{H}-\mathrm{H}-\mathrm{H}-\mathrm{M}-\mathrm{H}-\mathrm{M}-\mathrm{M})$, así como un gran total de 24 hombres ( 15 de mayoría relativa y 9 de representación proporcional) y 6 mujeres (3 de mayoría relativa y 3 de representación proporcional).

En resumidas cuentas:

Primero, el Consejo Estatal Electoral del Estado de Morelos, el 14 de junio de 2015, había aprobado el acuerdo IMPEPAC/CEE/177/2015, por el cual resolvieron, entre otras cosas, la forma de asignar los doce diputados por el principio de representación proporcional: 10 a mujeres y 2 a hombres (M-M-M-M-M-M-M-M-M-M-H-H). Con lo cual, como se puede apreciar en la Tabla 5, al cambiar a 9 hombres por mujeres y a 2 mujeres por hombres, no solamente afectaron a 11 de los 12 eventuales diputados tanto hombres como mujeres, sino además alteraron la asignación para dar un gran total de 17 hombres ( 15 de mayoría relativa y 2 de representación proporcional) y 13 mujeres ( 3 de mayoría relativa y 10 de representación proporcional):

Tabla 5

Diputados por el principio de representación proporcional en Morelos (asignación del Instituto Electoral local) 
Esta obra forma parte del acervo de la Biblioteca Jurídica Virtual del Instituto de Investigaciones Jurídicas de la UNAM www.juridicas.unam.mx

\begin{tabular}{|c|c|c|c|c|}
\hline Núm & Partido político & \multicolumn{2}{|c|}{ Asignado a: } & Género \\
\hline \multirow{2}{*}{1} & & $B V A$ & Propietaria & \multirow{2}{*}{ Mujer } \\
\hline & & NSC & Suplente & \\
\hline \multirow{2}{*}{2} & & NAPS & Propietaria & \multirow{2}{*}{ Mujer } \\
\hline & & $T M H V$ & Suplente & \\
\hline \multirow{2}{*}{3} & \multirow{2}{*}{ morena } & MHA & Propietaria & \multirow{2}{*}{ Mujer } \\
\hline & & MFGN & Suplente & \\
\hline \multirow{2}{*}{4} & \multirow{2}{*}{$\begin{array}{l}\text { MUN } \\
\text { MIUDADANO }\end{array}$} & $A L B$ & Propietaria & \multirow{2}{*}{ Mujer } \\
\hline & & CEMN & Suplente & \\
\hline \multirow{2}{*}{5} & & $L T H$ & Propietaria & \multirow{2}{*}{ Mujer } \\
\hline & & MACYM & Suplente & \\
\hline \multirow{3}{*}{6} & $\nabla$ & $D P Z L$ & Propietaria & \multirow{3}{*}{ Mujer } \\
\hline & PSD & & & \\
\hline & & $Y A G$ & Suplente & \\
\hline
\end{tabular}

DR @ 2018. Instituto de Investigaciones Jurídicas, UNAM, https://revistas.juridicas.unam.mx/index.php/derecho-electoral/issue/archive 
Esta obra forma parte del acervo de la Biblioteca Jurídica Virtual del Instituto de Investigaciones Jurídicas de la UNAM www.juridicas.unam.mx https://biblio.juridicas.unam.mx/bjv

https://revistas.juridicas.unam.mx/

DOI: http://dx.doi.org/10.22201/iij_.24487910e.2016.9.10095

\begin{tabular}{|c|c|c|c|c|}
\hline \multirow{2}{*}{7} & & Requerimiento & Propietaria & \multirow{2}{*}{ Mujer } \\
\hline & & Requerimiento & Suplente & \\
\hline \multirow{2}{*}{8} & & $D M H A$ & Propietaria & \multirow{2}{*}{ Mujer } \\
\hline & Hum: & $A B B$ & Suplente & \\
\hline \multirow{2}{*}{9} & & EBC & Propietaria & \multirow{2}{*}{ Mujer } \\
\hline & ali & PEMS & Suplente & \\
\hline \multirow{2}{*}{10} & \multirow{2}{*}{$\underset{\substack{\text { encuentro } \\
\text { social }}}{00}$} & $M J A$ & Propietaria & \multirow{2}{*}{ Mujer } \\
\hline & & $A L A M$ & Suplente & \\
\hline \multirow{2}{*}{11} & & FAMM & Propietario & \multirow[b]{2}{*}{ Hombre } \\
\hline & & MAVL & Suplente & \\
\hline \multirow{3}{*}{12} & & VMCS & Propietario & \multirow{3}{*}{ Hombre } \\
\hline & & Her & & \\
\hline & & HAL & supferite & \\
\hline
\end{tabular}

DR (C) 2018. Instituto de Investigaciones Jurídicas, UNAM, https://revistas.juridicas.unam.mx/index.php/derecho-electoral/issue/archive 
Esta obra forma parte del acervo de la Biblioteca Jurídica Virtual del Instituto de Investigaciones Jurídicas de la UNAM www.juridicas.unam.mx

FUENTE: Elaboración propia con los datos contenidos en el expediente SUP-JRC-680/2015 y sus acumulados.

Segundo, en contra de dicho acuerdo, varios candidatos y candidatas, así como algunos institutos políticos promovieron juicios para la protección de los derechos político-electorales del ciudadano local y recursos de inconformidad ante el Tribunal Electoral del Estado de Morelos. De esta forma, el 15 y 20 de julio, y el 10. de agosto del 2015, dicho Tribunal dictó diferentes resoluciones, identificadas como TEE-JDC255/2015-1 y sus acumulados TEE-JDC-262/2015, TEE-JDC-276/2015-1, TEE-JDC281/2015-1，TEE-JDC-287/2015-1，TEE-JDC-310/2015-1，TEE-RIN-347/2015-1，TEE-RIN350/2015-1 y TEE-RIN-356/2015-1, en las cuales modificó la asignación del Impepac, para otorgar las 12 diputaciones de representación proporcional a mujeres (M-M-M-MM-M-M-M-M-M-M-M). Por lo tanto, como se puede corroborar en la Tabla 6, al excluir a 2 hombres e incluir a 2 mujeres no solamente acabaron por alterar los dos últimos 2 lugares de representación proporcional, sino además alteraron la asignación para dar un gran total de 15 hombres (todos de mayoría relativa) y 15 mujeres ( 3 de mayoría relativa y 12 de representación proporcional), con lo cual alcanzarían una absoluta paridad de género, pero como punto de llegada:

Tabla 6

Diputados por el principio de representación proporcional en Morelos (asignación del Tribunal Electoral local)

\begin{tabular}{|c|c|c|c|c|}
\hline Núm. & Partido & \multicolumn{2}{|c|}{ Asignado a: } & Género \\
\hline \multirow{2}{*}{1} & & BVA & Propietaria & \multirow{2}{*}{ Mujer } \\
\hline & & NSC & Suplente & \\
\hline \multirow{2}{*}{2} & & NAPS & Propietaria & \multirow{2}{*}{ Mujer } \\
\hline & & TMHV & Suplente & \\
\hline
\end{tabular}


Esta obra forma parte del acervo de la Biblioteca Jurídica Virtual del Instituto de Investigaciones Jurídicas de la UNAM www.juridicas.unam.mx

Tabla 6

Diputados por el principio de representación proporcional en Morelos (asignación del Tribunal Electoral local)

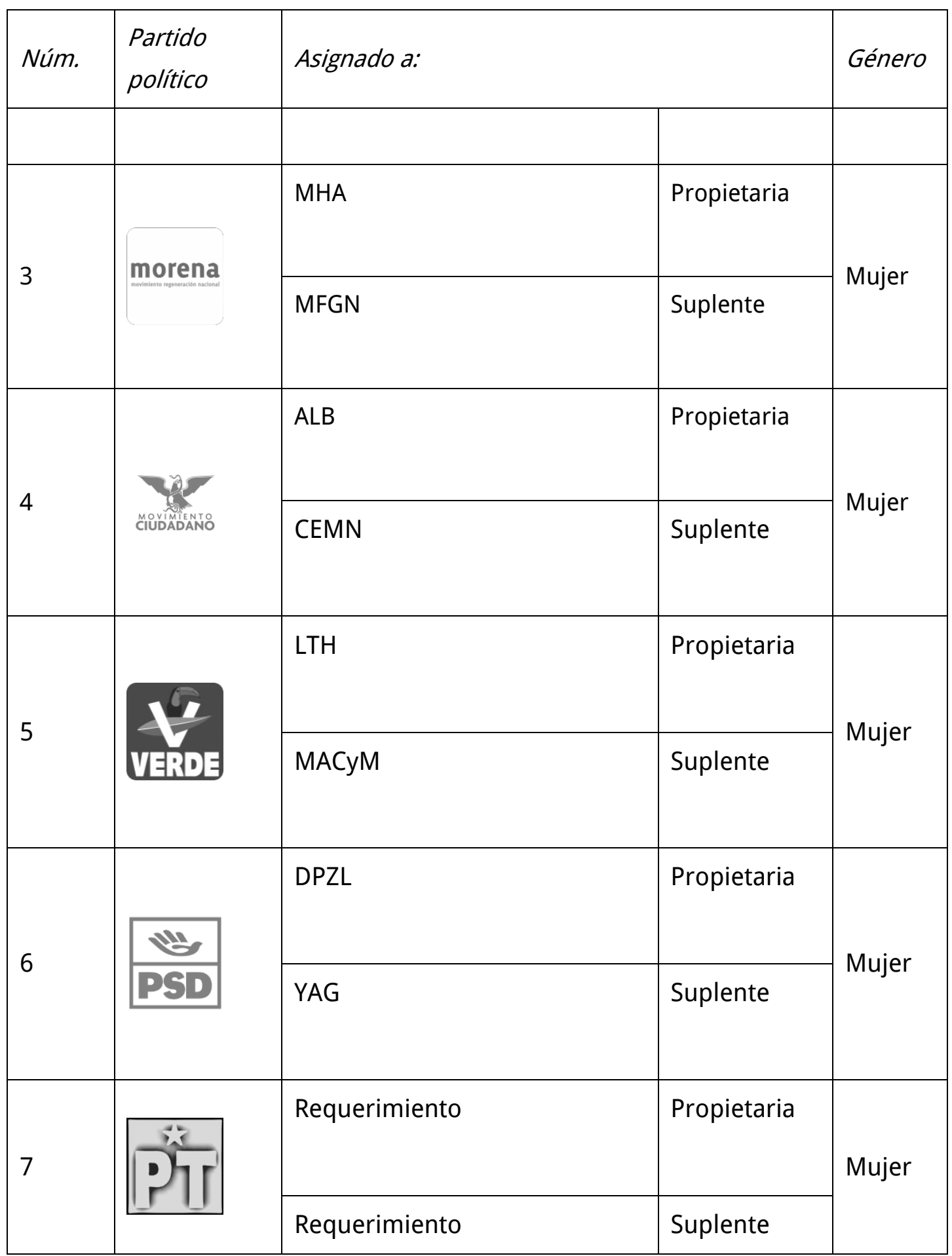

DR @ 2018. Instituto de Investigaciones Jurídicas, UNAM, https://revistas.juridicas.unam.mx/index.php/derecho-electoral/issue/archive 
Esta obra forma parte del acervo de la Biblioteca Jurídica Virtual del Instituto de Investigaciones Jurídicas de la UNAM www.juridicas.unam.mx

Tabla 6

Diputados por el principio de representación proporcional en Morelos (asignación del Tribunal Electoral local)

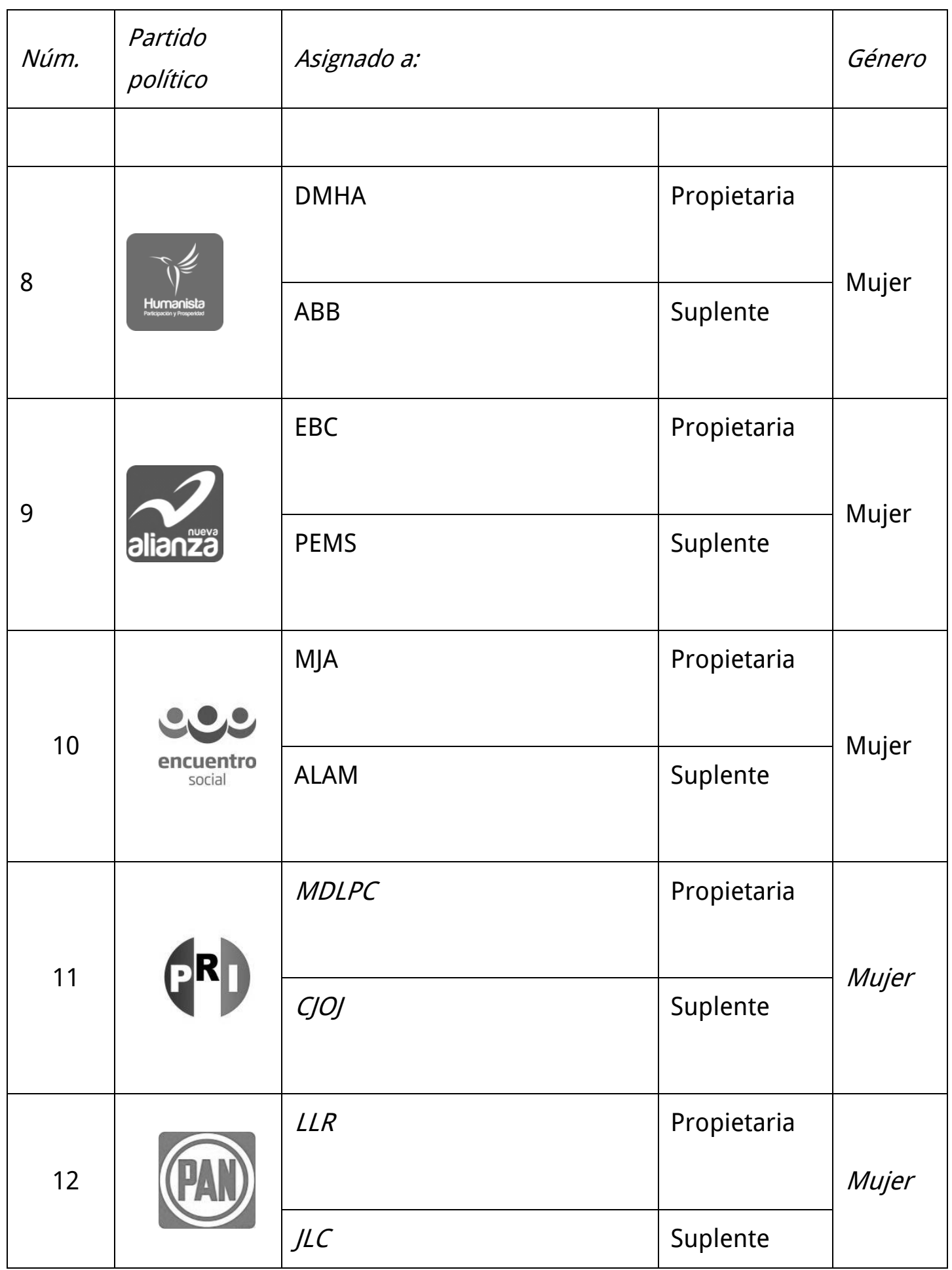

DR @ 2018. Instituto de Investigaciones Jurídicas, UNAM, https://revistas.juridicas.unam.mx/index.php/derecho-electoral/issue/archive 
Esta obra forma parte del acervo de la Biblioteca Jurídica Virtual del Instituto de Investigaciones Jurídicas de la UNAM www.juridicas.unam.mx

Tabla 6

Diputados por el principio de representación proporcional en Morelos (asignación del Tribunal Electoral local)

\begin{tabular}{|l|l|l|l|l|}
\hline Núm. & $\begin{array}{l}\text { Partido } \\
\text { político }\end{array}$ & Asignado a: & Género \\
\hline & & & & \\
\hline
\end{tabular}

FUENTE: Elaboración propia con los datos contenidos en el expediente SUP-JRC-680/2015 y sus acumulados.

Tercero, en contra de dicha resolución y de la asignación resultante, varios candidatos y candidatas, así como algunos institutos políticos promovieron juicios tanto de revisión constitucional como de protección de los derechos políticoelectorales del ciudadano ante la Sala Superior del Tribunal Electoral del Poder Judicial de la Federación. Dicha Sala resolvió revocar no solamente las sentencias dictadas por el Tribunal Electoral del Estado de Morelos, sino además el acuerdo emitido por el Consejo Estatal Electoral del Estado de Morelos, y ordenó que la asignación de las diputaciones por el principio de representación proporcional al Congreso del Estado de Morelos se hiciera de la forma precisada en sus consideraciones y, en consecuencia, como se puede percibir en la Tabla 7, asignar las diputaciones por el principio de representación proporcional: 9 a hombres y 3 a mujeres $(\mathrm{H}-\mathrm{H}-\mathrm{H}-\mathrm{H}-\mathrm{H}-\mathrm{H}-\mathrm{H}-\mathrm{H}-\mathrm{M}-\mathrm{H}-\mathrm{M}-\mathrm{M})$; y dar un gran total de 24 hombres (15 de mayoría relativa y 9 de representación proporcional) y 6 mujeres (3 de mayoría relativa y 3 de representación proporcional).

Tabla 7

Diputados por el principio de representación proporcional en Morelos (asignación de la Sala Superior del Tribunal Electoral del Poder Judicial de la Federación)

\begin{tabular}{|l|l|l|l|l|}
\hline Núm. & Partido político & \multicolumn{2}{|l|}{ Asignado a: } & Género \\
\hline 1 & PR & FAMM & Propietario & Hombre \\
\hline
\end{tabular}


Esta obra forma parte del acervo de la Biblioteca Jurídica Virtual del Instituto de Investigaciones Jurídicas de la UNAM www.juridicas.unam.mx https://biblio.juridicas.unam.mx/bjv

https://revistas.juridicas.unam.mx/

DOI: http://dx_doi.org/10.22201/iij_.24487910e_2016.9.10095

Tabla 7

Diputados por el principio de representación proporcional en Morelos (asignación de la Sala Superior del Tribunal Electoral del Poder Judicial de la Federación)

\begin{tabular}{|c|c|c|c|c|}
\hline \multirow[t]{2}{*}{ Núm. } & \multirow[t]{2}{*}{ Partido político } & \multicolumn{2}{|c|}{ Asignado a: } & \multirow[t]{2}{*}{ Género } \\
\hline & & $M A V L$ & Suplente & \\
\hline \multirow{2}{*}{2} & & VMCS & Propietario & \multirow{2}{*}{ Hombre } \\
\hline & & $H H C$ & Suplente & \\
\hline \multirow{3}{*}{3} & \multirow{3}{*}{ morena } & $M N A$ & Propietario & \multirow{3}{*}{ Hombre } \\
\hline & & & & \\
\hline & & $R S A$ & Suplente & \\
\hline \multirow{2}{*}{4} & \multirow{2}{*}{ MOUÁNO } & $J A C$ & Propietario & \multirow[b]{2}{*}{ Hombre } \\
\hline & & $A M B$ & Suplente & \\
\hline \multirow{2}{*}{5} & & FJEG & Propietario & \multirow{2}{*}{ Hombre } \\
\hline & VER日 & $R A T$ & Suplente & \\
\hline 6 & सै & $J C Y M$ & Propietario & Hombre \\
\hline
\end{tabular}

96

DR @ 2018. Instituto de Investigaciones Jurídicas, UNAM, https://revistas.juridicas.unam.mx/index.php/derecho-electoral/issue/archive 
Esta obra forma parte del acervo de la Biblioteca Jurídica Virtual del Instituto de Investigaciones Jurídicas de la UNAM www.juridicas.unam.mx

Tabla 7

Diputados por el principio de representación proporcional en Morelos (asignación de la Sala Superior del Tribunal Electoral del Poder Judicial de la Federación)

\begin{tabular}{|c|c|c|c|c|}
\hline \multirow[t]{2}{*}{ Núm. } & \multirow[t]{2}{*}{ Partido político } & \multicolumn{2}{|c|}{ Asignado a: } & \multirow[t]{2}{*}{ Género } \\
\hline & & $S A G M$ & Suplente & \\
\hline \multirow{2}{*}{7} & & $E B B$ & Propietario & \multirow{2}{*}{ Hombre } \\
\hline & & $R S G$ & Suplente & \\
\hline \multirow{2}{*}{8} & & $J E C$ & Propietario & \multirow{2}{*}{ Hombre } \\
\hline & & CFBL & Suplente & \\
\hline \multirow[b]{2}{*}{9} & & EBC & Propietaria & \multirow[b]{2}{*}{ Mujer } \\
\hline & & PEMS & Suplente & \\
\hline \multirow{2}{*}{10} & \multirow{2}{*}{$\underset{\substack{\text { encuentro } \\
\text { social }}}{e 0}$} & EEMC & Propietario & \multirow[b]{2}{*}{ Hombre } \\
\hline & & $C A R D$ & Suplente & \\
\hline 11 & & $B V A$ & Propietaria & Mujer \\
\hline
\end{tabular}

DR ( $)$ 2018. Instituto de Investigaciones Jurídicas, UNAM, https://revistas.juridicas.unam.mx/index.php/derecho-electoral/issue/archive 
Esta obra forma parte del acervo de la Biblioteca Jurídica Virtual del Instituto de Investigaciones Jurídicas de la UNAM www.juridicas.unam.mx

Tabla 7

Diputados por el principio de representación proporcional en Morelos (asignación de la Sala Superior del Tribunal Electoral del Poder Judicial de la Federación)

\begin{tabular}{|l|l|l|l|l|}
\hline Núm. & Partido político & \multicolumn{2}{|l|}{ Asignado a: } & Género \\
\hline & & NSC & Suplente & \\
\hline & & & & \\
\cline { 3 - 5 } & & NAPS & Propietaria & \\
\cline { 3 - 5 } & & TMHV & Suplente & \\
\hline
\end{tabular}

FUENTE: Elaboración propia con los datos contenidos en el expediente SUP-JRC-680/2015 y sus acumulados.

\section{IV. ¿LA PARIDAD DE GÉNERO COMO PUNTO DE LLEGADA?}

Como es sabido, un grupo de mujeres europeas "con experiencia en altas responsabilidades políticas", reunidas con motivo de la primera Cumbre Europea “Mujeres en el poder", adoptaron la Declaración de Atenas ${ }^{21}$ el 3 de noviembre de 1992. La Declaración comienza con un Preámbulo y en su desarrollo insiste:

Porque la igualdad formal y real entre las mujeres y hombres es un derecho fundamental del ser humano.

Porque las mujeres representan más de la mitad de la población. La democracia exige la paridad en la representación y en la administración de las naciones.

Porque las mujeres constituyen la mitad de las inteligencias y de las capacidades potenciales de la humanidad y su infra-representación en los puestos de decisión constituye una pérdida para el conjunto de la sociedad.

21 Véase Declaración de Atenas, disponible en http://www.urv.cat/media/upload/arxius/igualtat/JeanMonnet/2013/Lectura_recomendada_Declaracion_At enas_1992.pdf(página consultada el 16 de enero de 2016). 
Esta obra forma parte del acervo de la Biblioteca Jurídica Virtual del Instituto de Investigaciones Jurídicas de la UNAM www.juridicas.unam.mx

Porque una participación equilibrada de mujeres y hombres en la toma de decisiones puede generar ideas, valores y comportamientos diferentes, que vayan en la dirección de un mundo más justo y equilibrado tanto para las mujeres como para los hombres.

Porque la infra-representación de las mujeres en los puestos de decisión impide asumir plenamente los intereses y las necesidades del conjunto de la sociedad.

Proclamamos la necesidad de alcanzar un reparto equilibrado de los poderes públicos y políticos entre mujeres y hombres.

Reivindicamos la igualdad de participación de las mujeres y de los hombres en la toma de decisiones públicas y políticas.

Destacamos la necesidad de realizar modificaciones profundas en la estructura de los procesos de decisión con el fin de asegurar dicha igualdad.

Y continúa no solamente al insistir en que "La igualdad exige la paridad en la representación y administración de las naciones", sino además al invitar "a las mujeres y a los hombres de todos los países de Europa a reconocer la necesidad de alcanzar un equilibrio entre mujeres y hombres y a aceptar todas sus consecuencias con el fin de establecer una verdadera y duradera democracia".

Lo anterior parece sugerir que tanto la democracia como la igualdad exigen la paridad de género, pero no nada más como punto de partida sino como punto de llegada, y ha dado lugar a una concepción de "democracia" que podemos caracterizar como "democracia paritaria". 22 Si bien consideramos que es una demanda legítima que las mujeres no solamente estén en cargos de representación y de administración, sino además que tengan la mayor participación en dichos puestos y estén en condiciones de tomar decisiones en igualdad a los hombres, nos parece que al llevarlo al extremo se confunde el medio con el fin. La paridad de género, sobre todo como punto de llegada, no es un fin en sí mismo, sino tan sólo un medio, como punto de partida, para alcanzar la más amplia igualdad entre hombres y mujeres...

22 Véase Cobo, Rosa, "Política feminista y democracia paritaria”, Leviatán. Revista de Hechos e Ideas, segunda época, núm. 80, verano, 2000; “Democracia paritaria. Mujeres y hombres hacia la plena ciudadanía”, Metapolítica, vol. 5, núm. 18, abril-junio de 2001; y “Democracia paritaria y sujeto político feminista", Anales de la Cátedra Francisco Suárez, núm. 36, 2002. Véase también Sevilla Merino, Julia, Mujeres y ciudadanía: la democracia paritaria, Valencia, Institut Universitari D’Estudis de la Dona, Universitat de Valencia, 2004. 
Esta obra forma parte del acervo de la Biblioteca Jurídica Virtual del Instituto de Investigaciones Jurídicas de la UNAM www.juridicas.unam.mx

\section{A MODO DE CONCLUSIÓN: DE LA DEMOCRACIA PARITARIA A LA DEMOCRACIA SOCIETARIA}

Por supuesto que las sociedades modernas son mucho más complejas, y no bastaría con garantizar una paridad entre hombres y mujeres, porque en su interior también hay heterosexuales y homosexuales, laicos y religiosos, jóvenes y adultos mayores, nacionales y extranjeros, indígenas y no indígenas, patrones y trabajadores... y todos tendrían el mismo derecho a pedir la paridad o al menos la proporcionalidad.

Para concluir, nada más me resta reiterar que en el fondo el problema es que no hemos logrado superar la concepción mayoritaria de democracia y sustituirla con una concepción societaria de democracia en la cual todos... hombres y mujeres, heterosexuales y homosexuales, laicos y religiosos, jóvenes y adultos mayores, nacionales y extranjeros, indígenas y no indígenas, patrones y trabajadores... seamos socios en el autogobierno. ${ }^{23}$

23 Véase Stuart Mill, John, Considerations on Representative Government, Indianapolis, The Liberal Arts Press, 1958, pp. 102 y 103 (hay versión en español: Consideraciones sobre el gobierno representativo, trad. de Antonio Guzmán Balboa, México, Herrero Hermanos, 1966, pp. 120 y 121); y Dworkin, Ronald, "Introduction: The Moral Reading and the Majoritarian Premise", Freedom's Law. The Moral Reading of the American Constitution, Cambridge, Massachusetts, Harvard University Press, 1996, p. 17 (hay versión en español: "La lectura moral de la Constitución", trad. de Imer B. Flores, Cuestiones Constitucionales. Revista Mexicana de Derecho Constitucional, núm. 7, julio-diciembre de 2002, p. 25). Véase también Flores, Imer B., “Democracia y polarización: ¿(in)compatibilidad?”, en Díaz Müller, Luis T. (coord.), V Jornadas: Crisis y derechos humanos, México, UNAM, Instituto de Investigaciones Jurídicas, 2010, pp. 97-116; “Ronald Dworkin's Justice for Hedgehogs and Partnership Conception of Democracy (With a Comment to Jeremy Waldron's "A Majority in the Lifeboat")", Problema. Anuario de Filosofía y Teoría del Derecho, núm. 4, 2010, pp. 65-103; “La idea de democracia en contextos de polarización”, Frónesis. Revista de Filosofía Jurídica, Social y Política, vol. 19, núm. 2, mayo-agosto de 2012, pp. 201-220; y “The Problem of Democracy in Contexts of Polarization", en Cudd, Ann E. y Scholz, Sally J. (eds.), Philosophical Perspectives on Democracy in the 21st Century, Cham, Springer Verlag, 2014, pp. 103-117. 